\title{
PROMJENE SASTAVA I SADRŽAJA POLIFENOLNIH SPOJEVA U LISTOVIMA CRNIH SORATA TIJEKOM POJEDINIH FENOFAZA
}

\section{CHANGES IN THE COMPOSITION AND PHENOLIC COMPOUNDS CONTENT IN THE LEAVES OF BLACK GRAPEVINE VARIETIES DURING DIFFERENT GROWING STAGES}

\author{
Ž. Andabaka, F. Jakobović, D. Preiner, D. Stupić, Zvjezdana Marković, \\ E. Maletić, Jasminka Karoglan Kontić, Iva Šikuten, Petra Štambuk, \\ Ivana Tomaz, Marina Šeparović, M. Karoglan
}

\section{SAŽETAK}

Fenolni spojevi predstavljaju sekundarne biljne metabolite koji imaju vrlo važnu fiziološku i morfološku ulogu u rastu i reprodukciji biljke pružajući joj i zaštitu protiv patogena i predatora. Cilj ovoga istraživanja je dobiti pregled promjena u sastavu i sadržaju fenolnih spojeva odnosno flavonola, flavanola, hidroksicimetnih i hidroksibenzojevih kiselina prisutnih u listovima četiri različite crne sorte vinove loze. Ekstrakti su analizirani tekućinskom kromatografijom visoke djelotvornosti. Dobivenim rezultatima utvrđena je značajna varijabilnost u masenim udjelima fenolnih spojeva između sorata po pojedinim terminima uzorkovanja, kao i značajna varijabilnost u sadržaju fenolnih spojeva unutar iste sorte tijekom različitih termina uzorkovanja.

Ključne riječi: vinova loza, list, fenolni spojevi, crne sorte, tekućinska kromatografija

\begin{abstract}
Phenolic compounds represent secondary plant metabolites which play an important physiological and morphological role in plant growth and reproduction. They also provide a protection against pathogens and predators. The aim of this study is to obtain an overview of changes in the composition and phenolic compounds content, more precisely flavonols, flavanols, hydroxycimetic and hydroxybenzoic acids present in the leaves of four different grapevine varieties. The extracts were analyzed by high performance liquid chromatography. Based on the obtained results, significant variability in mass
\end{abstract}


Ž. Andabaka i sur.: Promjene sastava i sadržaja polifenolnih spojeva u listovima crnih sorata tijekom pojedinih fenofaza

shares of phenolic compounds between varieties was determined by individual sampling terms, as well as significant variability in the content of phenolic compounds within the same variety during different sampling terms.

Keywords: grapevine, leaf, phenolic compounds, red varieties, high performance liquid chromatography

\section{UVOD}

Vinova loza je biljna vrsta čija je domestifikacija započela na području zapadne Azije, Sjeverne Afrike i Mediterana (Bouby i sur., 2013.), a koja predstavlja jednu od gospodarski najznačajnijih biljnih vrsta u svijetu. Organi vinove loze sadrže mnoštva skupina spojeva od kojih su polifenoli jedni od najvažnijih (Bravo, 1998.). Važnost polifenola proizlazi iz njihove biološke aktivnosti i blagotvornih učinaka na ljudsko zdravlje (Shrikhande, 2000., Kennedy, 2008., En-Qin i sur., 2010.). Fenoli su skupina spojeva koja se sastoji od hidroksilne skupine $(-\mathrm{OH})$ vezane izravno na aromatski ugljikovodik. Najjednostavniji takav spoj je fenol $\left(\mathrm{C}_{6} \mathrm{H}_{5} \mathrm{OH}\right)$. Polifenoli štite list od štetnog UV zračenja te utječu na regulaciju biljnih hormona, posebno auksina. U listovima vinove loze smješteni su u epikutikularnom vosku i epidermi. Njihov sastav i sadržaj u listovima može biti indikator prilagodbe biljke na razinu i intenzitet UV zračenja tijekom pojedinih fenofaza razvoja (Keller, 2015., Peer i sur., 2007., Rozema i sur., 1997.). Dvije su osnovne grupe polifenola: neflavonoidi (fenolne kiseline) i flavonoidi (En-Qin i sur., 2010.). U odnosu na polifenole bobica grožđa, podaci o sadržaju i sastavu polifenola $u$ listovima vinove loze su oskudniji. Međutim, povećao se interes za njihovo proučavanje posljednjih godina. Prethodna su istraživanja fenolnih spojeva ukazala na povećanu zastupljenost flavonoida odnosno flavonola i flavan-3-ola, kao i neflavonoida odnosno derivata hidroksicimetne kiseline i derivata hidroksibenzojeve kiseline (Weber i sur., 1995., Schoedl i sur., 2012, Schoedl i sur., 2013.) u listovima vinove loze. Godišnji biološki ciklus rasta i razvoja vinove loze može se podijeliti na sedam fenofaza: suzenje ili plač, pupanje, rast i razvoj vegetacije, cvatnja i oplodnja, rast bobica, dozrijevanje grožđa, priprema za zimsko mirovanje i zimsko mirovanje (Coombe, 1995.). Cilj ovog rada je utvrditi promjene sastava i sadržaja polifenolnih spojeva u listovima autohtonih sorata i sorte Merlot vinove loze tijekom različitih fenofaza razvoja. 
Ž. Andabaka i sur.: Promjene sastava i sadržaja polifenolnih spojeva u listovima crnih sorata tijekom pojedinih fenofaza

\section{MATERIJALI I METODE}

Istraživanje je provedeno 2018. godine na četiri sorte (Plavac mali crni, Trnjak, Tribidrag i Merlot) posađene u kolekcijskim nasadima sorata na Vinogradarsko vinarskom pokušalištu Jazbina u Zagrebu. Vinogradarsko vinarsko pokušalište Jazbina je znanstveno-nastavni poligon, a nalazi se na blagim padinama planine Medvednice s južnom i jugozapadnom ekspozicijom. Najviša točka nalazi se na 302 m nadmorske visine. Pokusni nasad podizan je od 2001. do 2005. godine na podlozi $\mathrm{SO}_{4} \mathrm{~s}$ razmakom sadnje između redova od 2,1 m, a unutar reda 1,1 m. Uzgojni oblik je jednostrani kordonac. Sorta Merlot nalazi se u nasadu podignutom 2005. godine (sklop 2,1 x 1,2 m) u kojem je uzgojni oblik dvostrani Guyot.

Tijekom vegetacijske sezone, a počevši neposredno nakon cvatnje i završavajući u terminu tehnološke zrelosti sorata, uzorci listova prikupljali su se u pet termina (20. lipnja, 10. srpnja, 1. kolovoza, 23. kolovoza i 13. rujna). Jedan prosječan uzorak listova činilo je 3 do 5 listova s različitih trsova $i$ to $\mathrm{s}$ pozicije nasuprot 1 . grozdu na rodnoj mladici. Po završetku uzorkovanja, listovi su se spremili u papirnate vrećice $i$ čuvali na temperaturi od $-20^{\circ} \mathrm{C}$. Potom je uslijedilo liofiliziranje uzorka listova na kojima je prethodno uklonjena peteljka (liofilizator Alpha 1-2 LDPlus Martin Christ, Njemačka). Na uzorak mase usitnjenih listova od $180 \mathrm{mg}$ dodano je $10 \mathrm{~mL}$ ekstrakcijskog otapala $(20 \%$ acetonitril, $1 \%$ mravlja kiselina, $79 \%$ voda). Ekstrakcijska se smjesa ostavila na magnetskoj miješalici pri temperaturi od $48{ }^{\circ} \mathrm{C}$ u trajanju od $1 \mathrm{~h}$ i $30 \mathrm{~min}$. Koristio se tekućinski kromatograf visoke djelotvornosti Agilent 1100 serije za provođenje analize uzoraka. Kolona Luna Phenyl-Hexyl $(4,6 \times 250 \mathrm{~mm} ; 5 \mu \mathrm{m}$ veličina čestica (Phenomenex, SAD)) se koristila zbog razdvajanja pojedinih polifenola. U ovoj analizi koristila se $0,5 \%(\mathrm{v} / \mathrm{v})$ vodena otopina fosforne kiseline kao prvo otapalo, a kao drugo otapalo koristila se otopina acetonitrila, vode i fosforne kiseline $(50: 49,5: 0,5 ; \mathrm{v} / \mathrm{v} / \mathrm{v})$. Brzina protoka bila je $0,9 \mathrm{~mL} / \mathrm{min}$, volumen ubrizganog uzorka $20 \mu \mathrm{L}$, a temperatura kolone $50{ }^{\circ} \mathrm{C}$. Analize su provedene u tri ponavljanja, a rezultati su izraženi u $\mu \mathrm{g} / \mathrm{g}$ suhog lista. Kako bi se utvrdila značajnost razlika između sorata, provedena je jednosmjerna analiza varijance (one-way ANOVA). Istim statističkim postupkom utvrđena je statistički značajna razlika varijanata. Usporedba srednjih vrijednosti odnosno aritmetičkih sredina provedena je pomoću Duncan Multiple Range testa. Za statističku obradu podataka upotrijebljen je XLSTAT (Addinsoft, 2021). 
Ž. Andabaka i sur.: Promjene sastava i sadržaja polifenolnih spojeva u listovima crnih sorata tijekom pojedinih fenofaza

Za potrebe ovoga istraživanja obavljena su mjerenja dnevne temperature zraka $\left(\mathrm{C}^{\circ}\right)$ i intenziteta UV zračenja (W/ $\left.\mathrm{m}^{2} \mathrm{~s}\right)$. Sva potrebna mjerenja obavljena su na meteorološkoj stanici koja se nalazi u sklopu pokušališta „Jazbina“. Temperatura zraka mjerila se u periodu od 01.06. (prvo uzrokovanje je bilo 20.06) do 27.09. (zadnje uzorkovanje bilo je 13.09.) Minimalne, maksimalne $i$ srednje dnevne temperature zraka za navedeni period mogu se očitati na Grafikonu 1.

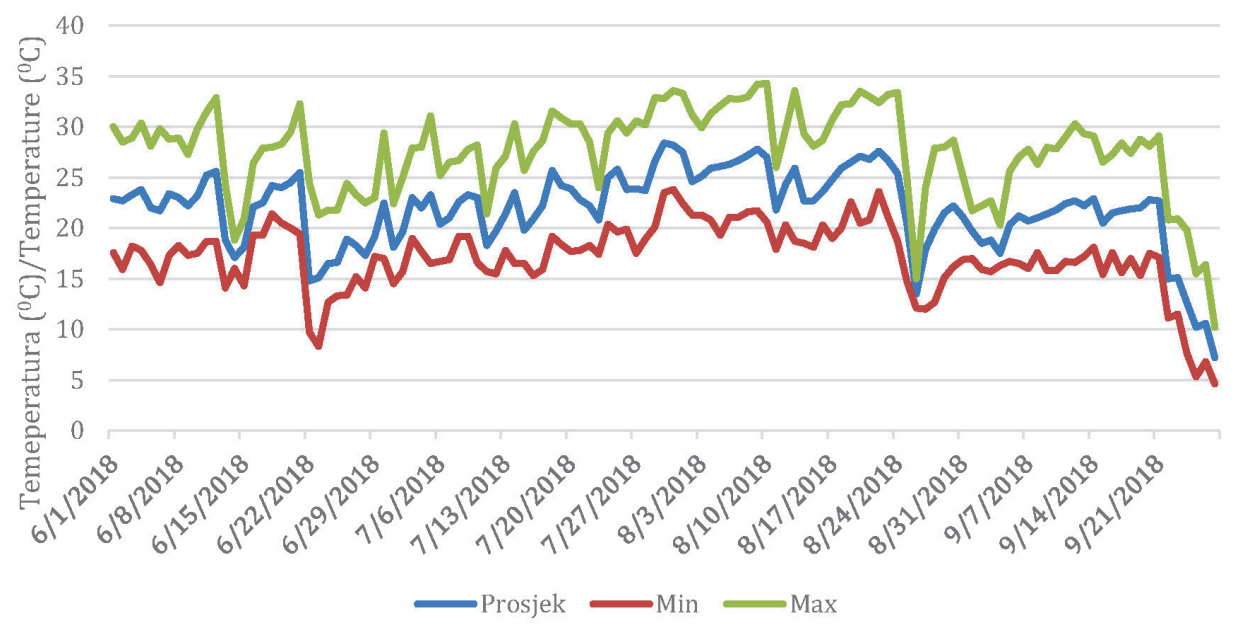

Grafikon 1. Dnevna temepratura zraka $\left(C^{\circ}\right)$

Graph 1 Daily air temeperature $\left(C^{\circ}\right)$

U razdoblju od 01.06. do 27.09. provedena su mjerenja intenziteta UV zračenja. Na Grafikonu 2. prikazani su intenziteti UV zračenja za navedeni period. 
Ž. Andabaka i sur.: Promjene sastava i sadržaja polifenolnih spojeva u listovima crnih sorata tijekom pojedinih fenofaza

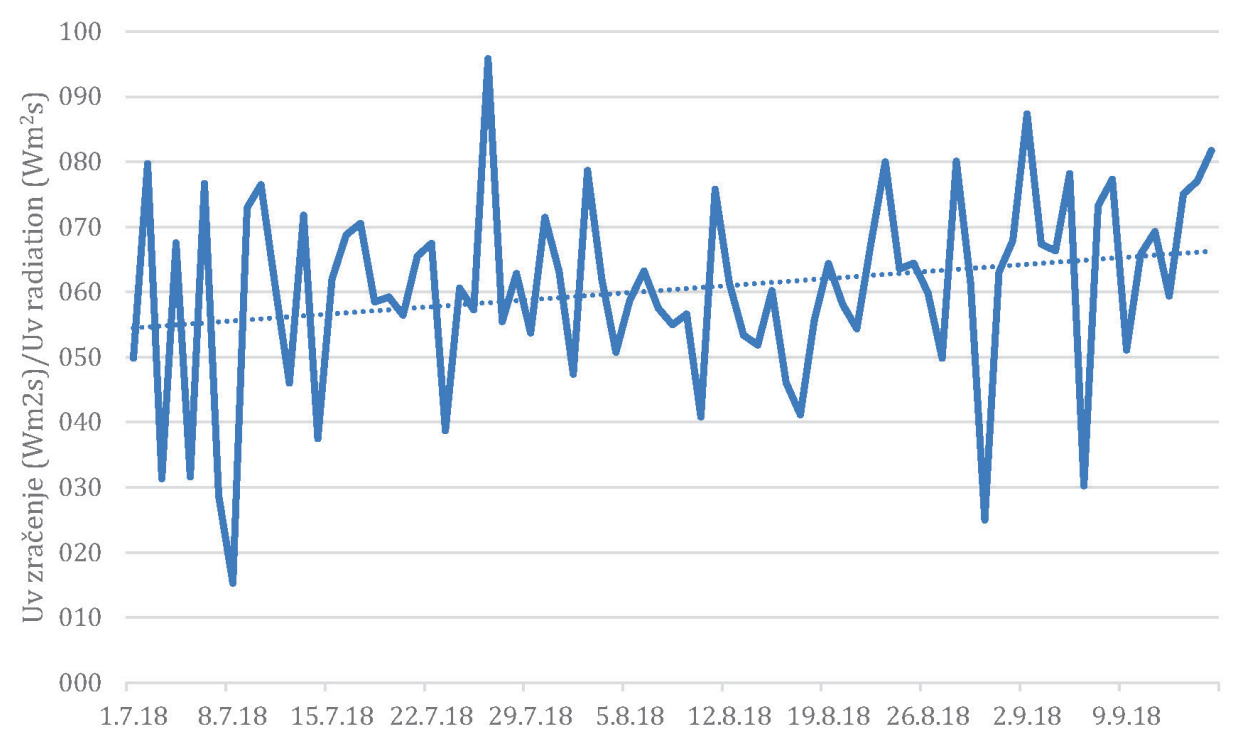

Grafikon 2. Intezitet $U V$ zračenja $\left(\mathrm{W} / \mathrm{m}^{2} \mathrm{~s}\right)$

Graph 2 Intensity of UV radiation $\left(\mathrm{W} / \mathrm{m}^{2} \mathrm{~s}\right)$

\section{REZULTATI I RASPRAVA}

Maseni udjeli fenolnih spojeva zastupljenih u listovima crnih sorata odabranih $\mathrm{u}$ ovom istraživanju mogu se vidjeti $\mathrm{u}$ Tablici 1 . Maseni udjeli izraženi su u $\mu \mathrm{g} / \mathrm{g}$ suhog lista. Od hidroksicimetnih kiselina $\mathrm{u}$ listovima pronađene su kaftarinska, kufeinska, kutarinska, kumarinska, fertarična i sinapinska kiselina. Od navedenih, najviše je zastupljena kaftarinska kiselina. Nadalje, od hidroksibenzojevih kiselina zastupljene su galna, prokatehinska i vanilijska kiselina. S druge strane, od flavonoida odnosno flavonola, u listovima su bili zastupljeni mircetin-3-O-glukonorid, mircetin-3-O-glukozid, rutin, kvercetin-3-O-glukonorid, kvercetin-3-O-glukozid, kemferol-3-O-glukonorid, kemferol-3-O-glukozid, kemferol-3-O-galaktozid i izoramnetin-3-O-glukozid. Također, od ostalih flavonoida, odnosno flavan-3-ola zastupljeni su galokatehin, procijanidin $\mathrm{B} 1$, epigalokatehin, procijanidin $\mathrm{B} 3$, katehin, procijanidin $\mathrm{B} 4$, procijanidin B2 i epikatehin. Među utvrđenim grupama fenolnih spojeva možemo istaknuti kako su flavonoli i hidroksicimetne kiseline zastupljeni $\mathrm{u}$ većoj mjeri za razliku od flavanola i hidroksibenzojevih kiselina (Tablica 1). 
Ž. Andabaka i sur.: Promjene sastava i sadržaja polifenolnih spojeva u listovima crnih sorata tijekom pojedinih fenofaza

Tablica 1. Maseni udjeli fenolnih spojeva u istraživanim sortama $\mu \mathrm{g} / \mathrm{g}$

Table 1 Mass share of phenolic compounds in the studied varieties $\mu \mathrm{g} / \mathrm{g}$

\begin{tabular}{|l|c|c|c|c|c|}
\hline \multicolumn{1}{|c|}{$\begin{array}{c}\text { Sorta/ } \\
\text { Variety }\end{array}$} & $\begin{array}{c}\text { Termin } \\
\text { uzorkovanja/ } \\
\text { Sampling } \\
\text { terms }\end{array}$ & $\begin{array}{c}\text { Flavonoli/ } \\
\text { Flavonols }\end{array}$ & $\begin{array}{c}\text { Flavanoli/ } \\
\text { Flavanols }\end{array}$ & $\begin{array}{c}\text { Hidroksicimetne } \\
\text { kiseline/ } \\
\text { Hydroxycinnamic } \\
\text { acids }\end{array}$ & $\begin{array}{c}\text { Hiroksibenzojeve } \\
\text { kiseline/ } \\
\text { Hydroxybenzoic } \\
\text { acids }\end{array}$ \\
\hline Merlot & I & $34276.190 \mathrm{a}$ & $763.890 \mathrm{~b}$ & $4180.440 \mathrm{a}$ & $193.390 \mathrm{a}$ \\
\hline $\begin{array}{l}\text { Plavac } \\
\text { mali crni }\end{array}$ & I & $31516.690 \mathrm{~b}$ & $813.370 \mathrm{a}$ & $3337.610 \mathrm{~b}$ & $162.535 \mathrm{~b}$ \\
\hline Trnjak & I & $24597.320 \mathrm{c}$ & $419.705 \mathrm{~d}$ & $2879.390 \mathrm{c}$ & $206.720 \mathrm{a}$ \\
\hline Tribidrag & I & $21683.815 \mathrm{~d}$ & $495.895 \mathrm{c}$ & $1689.445 \mathrm{~d}$ & $125.500 \mathrm{c}$ \\
\hline Merlot & II & $42037.535 \mathrm{a}$ & $1086.140 \mathrm{~b}$ & $4584.235 \mathrm{a}$ & $271.055 \mathrm{~b}$ \\
\hline $\begin{array}{l}\text { Plavac } \\
\text { mali crni }\end{array}$ & II & $38407.795 \mathrm{~b}$ & $1266.745 \mathrm{a}$ & $3792.220 \mathrm{~b}$ & $289.915 \mathrm{a}$ \\
\hline Trnjak & II & $25920.470 \mathrm{c}$ & $506.820 \mathrm{c}$ & $2629.240 \mathrm{c}$ & $264.845 \mathrm{~b}$ \\
\hline Tribidrag & II & $22113.620 \mathrm{~d}$ & $559.980 \mathrm{c}$ & $1973.155 \mathrm{~d}$ & $181.125 \mathrm{c}$ \\
\hline $\begin{array}{l}\text { Plavac } \\
\text { mali crni }\end{array}$ & III & $41036.030 \mathrm{a}$ & $1548.365 \mathrm{a}$ & $5295.205 \mathrm{a}$ & $395.210 \mathrm{~b}$ \\
\hline Trnjak & III & $31734.625 \mathrm{c}$ & $1108.050 \mathrm{~b}$ & $4470.680 \mathrm{c}$ & $426.330 \mathrm{a}$ \\
\hline Merlot & III & $39545.535 \mathrm{~b}$ & $1037.490 \mathrm{c}$ & $4625.260 \mathrm{~b}$ & $254.120 \mathrm{~d}$ \\
\hline Tribidrag & III & $25019.445 \mathrm{~d}$ & $976.070 \mathrm{~d}$ & $4271.030 \mathrm{~d}$ & $302.795 \mathrm{c}$ \\
\hline Merlot & IV & $35521.790 \mathrm{a}$ & $1587.905 \mathrm{a}$ & $5705.800 \mathrm{~b}$ & $312.660 \mathrm{~d}$ \\
\hline $\begin{array}{l}\text { Plavac } \\
\text { mali crni }\end{array}$ & IV & $34134.440 \mathrm{~b}$ & $1549.775 \mathrm{~b}$ & $5824.050 \mathrm{a}$ & $328.840 \mathrm{c}$ \\
\hline Trnjak & IV & $29586.435 \mathrm{c}$ & $1456.445 \mathrm{c}$ & $4404.490 \mathrm{c}$ & $530.285 \mathrm{a}$ \\
\hline Tribidrag & IV & $24757.970 \mathrm{~d}$ & $1139.825 \mathrm{~d}$ & $3994.970 \mathrm{~d}$ & $347.965 \mathrm{~b}$ \\
\hline Merlot & V & $35521.790 \mathrm{a}$ & $1587.905 \mathrm{a}$ & $5705.800 \mathrm{~b}$ & $312.660 \mathrm{~d}$ \\
\hline $\begin{array}{l}\text { Plavac } \\
\text { mali crni }\end{array}$ & V & $34134.440 \mathrm{~b}$ & $1549.775 \mathrm{~b}$ & $5824.050 \mathrm{a}$ & $328.840 \mathrm{c}$ \\
\hline Trnjak & V & $29586.435 \mathrm{c}$ & $1456.445 \mathrm{c}$ & $4404.490 \mathrm{c}$ & $530.285 \mathrm{a}$ \\
\hline Tribidrag & V & $24757.970 \mathrm{~d}$ & $1139.825 \mathrm{~d}$ & $3994.970 \mathrm{~d}$ & $347.965 \mathrm{~b}$ \\
\hline
\end{tabular}

*srednje vrijednosti označene različitim slovima između sorata razlikuju se na razini $\mathrm{p}<0.05$ korištenjem Duncan's multiple-range testa/ mean values marked with different letters between varieties differ at the level of $\mathrm{p}<0.05$ using Duncan's multiple-range test

U prvom terminu uzorkovanja kod sorte Merlot zabilježeni su prosječno najviši maseni udjeli flavanola $(34276,19 \mu \mathrm{g} / \mathrm{g})$, hidroksicimetnih kiselina $(4180,44 \mu \mathrm{g} / \mathrm{g})$ i hidroksibenzojevih kiselina $(193,39 \mu \mathrm{g} / \mathrm{g})$. Prosječno najniži maseni udjeli u sadržaju flavonola $(21683,815 \mu \mathrm{g} / \mathrm{g})$, hidroksicimetnih kiselina 
Ž. Andabaka i sur.: Promjene sastava i sadržaja polifenolnih spojeva u listovima crnih sorata tijekom pojedinih fenofaza

$(1689,445 \mu \mathrm{g} / \mathrm{g})$ i dihroksibenzojevih kiselina $(125,50 \mu \mathrm{g} / \mathrm{g})$ zabilježeni su kod sorte Tribidrag. Najviši prosječni udjel flavanola zabilježen je kod sorte Plavac mali crni $(813,37 \mu \mathrm{g} / \mathrm{g})$ dok je najniži prosječni udjel utvrđen kod sorte Trnjak $(419,705 \mu \mathrm{g} / \mathrm{g})$. Prvo uzorkovanje obavljeno je nakon cvatnje vinove loze. U ovoj fenofazi uzgoja vinove loze listovi su gotovo posve razvijeni te samostalno obavljaju fotosintezu. Prosječne temperature zraka u periodu od 01.06. do 20.6. (prvi termin uzorkovanja) kretale su se od $18^{\circ} \mathrm{C}$ do $25^{\circ} \mathrm{C}$. Također, u navedenom terminu tri dana bilježe najviše izmjerenu temperaturu od $33^{\circ} \mathrm{C}$ (Grafikon 1.). Takve vremenske prilike omogućile su proces fotosinteze koji je potaknuo nastajanje fenola kao sekundarnih metabolita.

U drugom terminu uzorkovanja prosječno najviši maseni udjeli flavonola $(42037.535 \mu \mathrm{g} / \mathrm{g})$ i hidroksicimetnih kiselina $(4584.235 \mu \mathrm{g} / \mathrm{g})$ zabilježeni su kod sorte Merlot, a kod Plavca malog crnog flavanola $(1266.745 \mu \mathrm{g} / \mathrm{g})$ i hidroksibenzojevih kiselina $(289.915 \mu \mathrm{g} / \mathrm{g})$. Kod sorte Tribidrag, zabilježeni su prosječno najniži maseni udjeli analiziranih fenolnih kiselina i flavonola. Prosječne temperature izmjerene između prvog i drugog perioda uzorkovanja iznosile su od $15^{\circ} \mathrm{C}$ do $23^{\circ} \mathrm{C}$. Samo u jednom danu navedenog termina maksimalna temperatura iznosila je $30^{\circ} \mathrm{C}$ (Grafikon 1.).

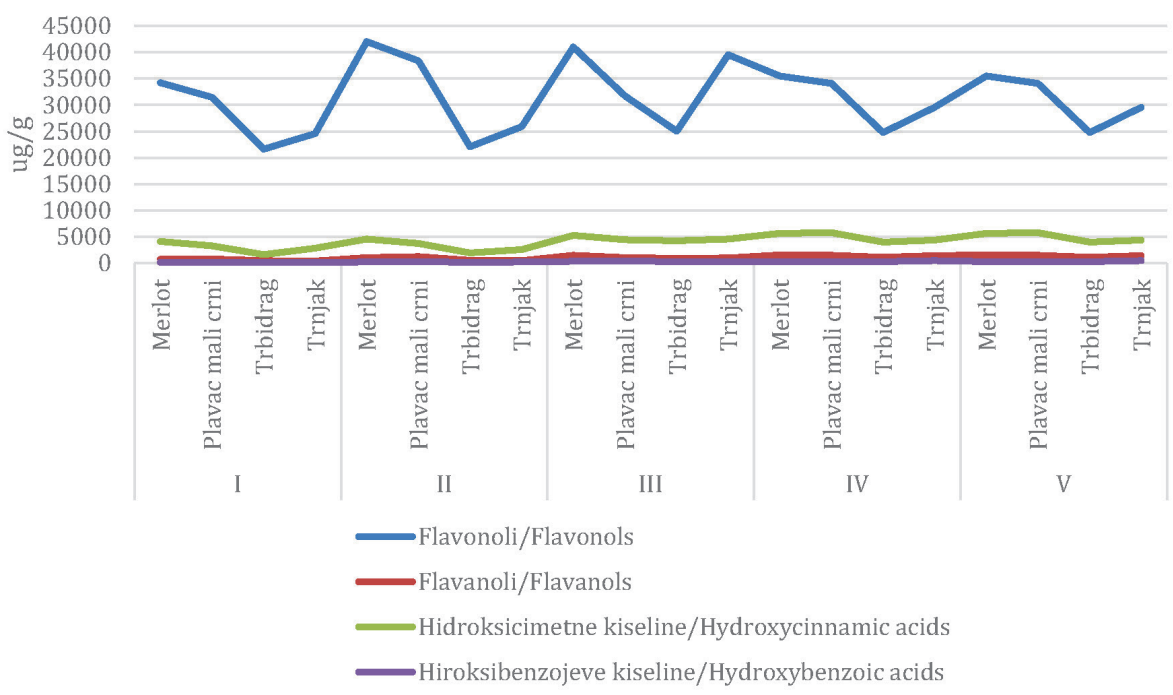

Grafikon 3. Promjene masenih udjela fenolnih spojeva u istraživanim sortama $(\mu \mathrm{g} / \mathrm{g})$ Graph 3 Changes in mass shares of phenolic compounds in the studied varieties $(\mu \mathrm{g} / \mathrm{g})$ 
Ž. Andabaka i sur.: Promjene sastava i sadržaja polifenolnih spojeva u listovima crnih sorata tijekom pojedinih fenofaza

U trećem terminu uzorkovanja koje je obavljeno 1. kolovoza prosječno najviši maseni udjeli flavonola $(41036.03 \mu \mathrm{g} / \mathrm{g})$, flavanola $(1548.365 \mu \mathrm{g} / \mathrm{g}) \mathrm{i}$ hidroksicimetnih kiselina $(5295.205 \mu \mathrm{g} / \mathrm{g})$ zabilježni su kod sorte Plavac mali crni te hidroksibenzojeve kiseline $(426.33 \mu \mathrm{g} / \mathrm{g}) \mathrm{kod}$ sorte Trnjak. Prosječno najniže vrijednosti masenih udjela flavonola $(25019.445 \mu \mathrm{g} / \mathrm{g})$, flavanola $(976.07 \mu \mathrm{g} / \mathrm{g})$ i hidroksicimetnih kiselina $(4271.03 \mu \mathrm{g} / \mathrm{g})$ utvrđeni su kod sorte Tribidrag kao i hidroksibezojevih kiselina $(254.12 \mu \mathrm{g} / \mathrm{g})$ kod sorte Merlot. U razdoblju između drugog i trećeg termina uzorkovanja prikupljeni su podaci o temperaturi zraka. Prosječna temperatura iznosila je od $23^{\circ} \mathrm{C}$ do $26^{\circ} \mathrm{C}$, dok je pojedinih dana maksimalna temperatura iznosila i više od $35^{\circ} \mathrm{C}$ (Grafikon 1.).

U četvrtom terminu uzorkovanja, prosječno najviši maseni udjeli flavonola $(35521.79 \mu \mathrm{g} / \mathrm{g})$ i flavanola $(1587.905 \mu \mathrm{g} / \mathrm{g})$ zabilježeni su kod sorte Merlot, hidroksicimetne $(5824.05 \mu \mathrm{g} / \mathrm{g})$ kod sorte Plavac mali crni te hidroksibenzojeve $(530.285 \mu \mathrm{g} / \mathrm{g})$ kod sorte Trnjak. Najniže prosječne masene udjele flavonola, flavanola i hidroksicimetnih kiselina zabilježene su kod sorte Merlot te hidroksibenzojeve kiseline kod sorte Plavac mali crni. U periodu između trećeg i četvrtog uzorkovanja izmjerene su visoke temperature zraka. Preciznije, prosječne temperature kretale su se od $20^{\circ} \mathrm{C}$ do $29{ }^{\circ} \mathrm{C}$, a nekoliko dana u terminu od 1.08. do 23.08. pokazuje temperature veće od $30^{\circ} \mathrm{C}$ (Grafikon 1.). U trećem i u četvrtom terminu, sorte pokazuju veće vrijednosti fenolnih spojeva u odnosu na prvo uzorkovanje. Sukladno tome, povećane temperature zraka i UV zračenja doprinijele su značajnijoj sintezi fenolnih spojeva te su se na taj način sorte prilagodile uvjetima okoliša (Kolb i sur., 2001).

U petom i posljednjem terminu uzorkovanja prosječno najviši maseni udjeli flavonola $(35521.79 \mu \mathrm{g} / \mathrm{g})$ i flavanola $(1587.905 \mu \mathrm{g} / \mathrm{g})$ zabilježeni su kod sorte Merlot, hidroksicimetne kiseline $(5824.05 \mu \mathrm{g} / \mathrm{g})$ kod sorte Plavac mali crni te hidroksibenzojeve kiseline $(530.285 \mu \mathrm{g} / \mathrm{g})$ kod sorte Trnjak. Prosječno najniže vrijednosti masenih udjela flavonola $(24757.97 \mu \mathrm{g} / \mathrm{g})$, flavanola $(1139.825 \mu \mathrm{g} / \mathrm{g})$, hiroksicimetnih kiselina $(3994.97 \mu \mathrm{g} / \mathrm{g})$ zabilježene su kod sorte Tribidrag i hidroksibenzojevih kiselina $(347.965 \mu \mathrm{g} / \mathrm{g})$ kod sorte Plavac mali crni.

Također, u terminu od četvrtog do petog uzorkovanja dolazi do općenitog smanjenja fotosintetske aktivnosti i do starenja samog lista. U prilog istome, temperature mjerene između navedenog termina bile su niže $\mathrm{u}$ odnosu na ostale termine odnosno prosječne temperature iznosile su od $10{ }^{\circ} \mathrm{C}$ do $23{ }^{\circ} \mathrm{C}$ (Grafikon 1.) Navedeni okolinski uvjeti mogu značajno utjecati na sintezu fenolnih spojeva (Schoedl i sur., 2012). 
Ž. Andabaka i sur.: Promjene sastava i sadržaja polifenolnih spojeva u listovima crnih sorata tijekom pojedinih fenofaza

\section{ZAKLJUČAK}

$\mathrm{Na}$ temelju istraživanja provedenog tijekom 2018. godine o promjenama $\mathrm{u}$ sastavu i sadržaju fenolnih spojeva (flavonola, hidroksicimetnih kiselina, hidroksibenzojevih kiselina, flavanola) u listovima sorata 'Plavac mali crni', 'Trnjak', 'Tribidrag', i 'Merlot', možemo utvrditi kako postoje značajne razlike u masenim udjelima fenolnih spojeva između sorata po pojedinim terminima uzorkovanja. Isto tako, utvrđene su statistički značajne razlike u masenim udjelima fenolnih spojeva iste sorte tijekom različitih termina uzorkovanja. Sadržaj fenolnih spojeva ovisi o okolišnim uvjetima kao što su UV zračenje i temperature zraka.

Najzastupljenija grupa ispitivanih fenolnih spojeva su hidroksicimetne kiseline, a slijede ih flavonoli, flavanoli te hidroksibenzojeve kiseline.

\section{NAPOMENA}

Rezultati prezentirani u radu nastali su kao rezultat znanstvenog projekta HRZZ IP-06-2016: „Vinogradarstvo i klimatske promjene na području Hrvatske (VITCLIC)“.

\section{LITERATURA}

1. Addinsoft (2021.): XLSTAT statistical and data analysis solution. New York, USA.

2. Bravo, L. (1998.): Polyphenols: Chemistry, Dietary Sources, Metabolism, and Nutritional. PubMed. 56 (11): 317-333.

3. Bouby, L., Figueiral, I., Bouchette, A., Rovira, N., Ivorra, S., Lacombe, T., Pastor, T., Picq, S., Marinval, P., Terral, J-F. (2013.): Bioarchaeological Insights into the Process of Domestication of Grapevine (Vitis vinifera L.) during Times in Southern France. PLOS ONE 8(5): e63195.

4. Coombe, B.G. (1995.): Adoption of a system for identifying grapevine growth stages. Aust. J. Grape Wine Res. 1: 110-110.

5. En-Qin, X., Gui-Fang, D., Ya-Jun, G., Hua-Bin, L. (2010.): Biological Activities of Polyphenols from Grapes. Int. J. Mol. Sci. 11: 622-646.

6. Keller M.(2015.): The science of grapevine. Accademic press, London.

7. Kennedy, J.A. (2008.): Grape and wine phenolic: Observations and recent findings. Cien Inv Agr. 35: 107-120.

8. Kolb, A.C., Käser, M.A., Kopecký, J., Zotz, G., Riederer, M., Pfündel, E.E. (2001.): Effects of Natural Intensities of Visible and Ultraviolet Radiation on Epidermal Ultraviolet Screening and Photosynthesis in Grape Leaves. Plant Physiology 127: 863-875. 
Ž. Andabaka i sur.: Promjene sastava i sadržaja polifenolnih spojeva u listovima crnih sorata tijekom pojedinih fenofaza

9. Peer, W. A., Murphy, A. S. (2007.): Flavonoids and auxin transport: modulators or regulators? Trends in Plant Science 12 (12): 556-63.

10. Rozema, J., van de Staaij, J., Bjorn, L. O., Caldwell, M. (1997.): UV-B as an environmental factor in plant life: Stress and regulation. Trends in Ecology \& Evolution 12 (1): 22-8.

11. Schoedl, K., Schuhmacher, R. i Forneck, A. (2013.): Correlating physiological parameters with biomarkers for UV-B stress indicators in leaves of grapevine cultivars Pinot noir and Riesling. Journal of Agricultural Science 151: 198-200.

12. Schoedl, K., Schuhmacher, R., Forneck, A. (2012.): Studying the polyphenols of grapevine leaves according to age and insertion level under controlled conditions. Scientia Horticulturae 141: 37-41.

13. Shrikhande, A.J. (2000.): Wine by-products with health benefits. Food Res. Internat 33: 469-474.

14. Weber, B., Hoesch, L., rast, D.M. (1995.): Protocatechualdehyde and other phenols as cell wallcomponents of grapevine leaves. Phytochemistry 40(20): 433-437

Adresa autora - Author's adress:

doc. dr. sc. Željko Andabaka, e-mail:zandabaka@agr.hr $\quad 20.12 .2020$.

izv. prof. dr. sc. Darko Preiner,

doc. dr. sc. Domagoj Stupić,

doc. dr. sc. Zvjezdana Marković,

prof. dr. sc. Edi Maletić,

prof. dr.sc. Jasminka Karoglan Kontić,

Iva Šikuten, mag. ing. agr.

dr.sc. Ivana Tomaz,

Marina Šeparović, mag. ing. agr.

izv. prof. dr. sc. Marko Karoglan

Agronomski fakultet Sveučilište u Zagrebu

Svetošimunska cesta 25, 10000 Zagreb, Hrvatska

Filip Jakobović, mag.ing.agr. student Agronomskog fakulteta

Sveučilište u Zagrebu, Svetošimunska cesta 25, 10000 Zagreb, Hrvatska, U1. Stjepana Radića 60, 34335 Vetovo, Hrvatska

Petra Štambuk, mag. ing. agr.

Znanstveni centar izvrsnosti za bioraznolikost i molekularno oplemenjivanje bilja Svetošimunska cesta 25, 10000 Zagreb, Hrvatska 